\title{
AC 2009-1894: THE DEVELOPMENT OF A NATIONAL WORKSHOP TO TEACH NORWEGIAN PH.D. STUDENTS IN ENGINEERING AND SCIENCE HOW TO COMMUNICATE RESEARCH
}

\section{Michael Alley, Pennsylvania State University}

Michael Alley is an associate professor of engineering communication at Pennsylvania State University. He is the author of The Craft of Scientific Presentations (2002, Springer-Verlag). In addition, he regularly teaches presentation workshops at several research institutions in the United States and Europe. For the Norwegian national workshop discussed in this paper, he served as a lecturer for the formal classes and a principal instructor for the parallel critique sessions.

\section{Are Magnus Bruaset, Simula Research Laboratory}

Are Magnus Bruaset holds a PhD in mathematical modeling from the University of Oslo. Since 2007, he has served as the assistant director of the Simula School of Research and Innovation. In addition, since late 2004, he has built up Simula's research group in Computational Geosciences in close collaboration with StatoilHydro. He still leads this research group. Bruaset is also a professor at Department of Informatics, University of Oslo. For this national workshop, he served the lead organizer and as a principal instructor in the critique sessions.

\section{Melissa Marshall, Pennsylvania State University}

Melissa Marshall is a lecturer with the Department of Communication Arts \& Sciences at Pennsylvania State University, where she has been teaching since 2004. She has taught workshops on scientific presentations at the University of Illinois, Cornell University, the Center for Disease Control, and Laval University (in Quebec). For this Norwegian national workshop, she served as a lecturer for the formal classes and a principal instructor for the parallel critique sessions.

\section{Marianne M. Sundet, Simula Research Laboratory}

Marianne M. Sundet holds a Master of Philosophy in Literature Studies and works as an advisor at Simula Research Laboratory. For the Norwegian national workshop discussed in this paper, she was instrumental in organizing the event, including design and dissemination of information to potential participants and the public.

\section{Sarah Zappe, Pennsylvania State University}

Dr. Sarah Zappe is the Director of Assessment and Instructional Support in the Leonhard Center for the Enhancement of Engineering Education at Pennsylvania State University. Her background is in educational psychology with an emphasis on educational testing and assessment. 


\title{
Development of a National Workshop to Teach Norwegian Ph.D. Students in Engineering and Science How to Communicate Research
}

\author{
Key Words: graduate students, international, communication
}

\begin{abstract}
To succeed, research engineers and scientists have to be able to communicate their work to both technical and non-technical audiences. Typically, graduate students in engineering and science do not receive formal instruction on the skills particular to communicating research. Instead, graduate students pick up these skills from their research advisors during the preparation of papers and presentations. Some universities do offer formal workshops, but these workshops usually have not been assessed by anyone outside the institution, do not provide individual feedback to the student, and try to address the needs of graduate students from all disciplines. To address these deficiencies, Simula Research Laboratory in Norway has collaborated with faculty from Pennsylvania State University to pilot a national workshop (given in English) for Norwegian Ph.D. students on communicating scientific research. Funded primarily by Norwegian industries, the 3-day workshop was divided into three segments: (1) making research presentations to a technical audience, (2) writing research papers and dissertations to technical audiences, and (3) making research presentations to general audiences.
\end{abstract}

The first two segments, on making research presentations and writing research documents to technical audiences, were based on a workshop series that was developed at national laboratories in the U.S., taught to more than 1000 professionals and graduate students, and formally tested on more than 400 engineering and science graduate students at five different universities. The segment on research presentations to technical audiences called upon participants to prepare a 10-12 minute talk about their research, to submit slides for review before the workshop, to attend the formal class on research presentations during the workshop, to revise their presentations based on that class, and then to give and participate in critique sessions of these talks. The second segment on writing research documents called upon participants to prepare and submit a summary of their research before the workshop begins. This summary was used by participants for critiquing exercises during the formal part of the writing class. Moreover, common weaknesses of these summaries were emphasized during the formal class portion.

The third segment, communicating research to the general public, had the goal of teaching participants how to give general audiences what Richard Feynman called an "honest" understanding of the work. The content for this segment arose from an examination of successful general audience presentations, given by well known figures such as Robert Ballard and Janine Benyus. This segment had its premiere at the national workshop. 
Through the distribution of almost 1900 brochures, Simula attempted to invite every Ph.D. student in engineering and science across Norway to apply, and 232 did so. That so many Ph.D. students applied for the first offering of such a workshop indicates the need for this type of education. In total, $56 \mathrm{Ph}$.D. students were selected for admission - the additional 12 slots were reserved for postdoctoral researchers designated by the sponsors and Simula. The 68 participants represented 28 different countries, 25 different first languages, and every continent except for Antarctica. Assessment of the workshop is ongoing and includes surveys of the participants as well as comparisons of the presentation slides created by participants before the workshop with slides created after the participants received workshop instruction.

\section{Introduction}

The challenge for graduate students to communicate their research is high. Although graduate students are just learning the technical details of their respective research areas, graduate students face the same expectations for their papers and conference presentations as what longstanding researchers in the field face. ${ }^{1}$ For instance, graduate students are expected to know how much depth to present, what details to emphasize, and what wording to use.

To help graduate students with this challenge, faculty advisors in engineering and science spend much time mentoring their students. ${ }^{2}$ Typically, advisors critique dry-runs of conference presentations and provide feedback on drafts of documents. Although faculty mentors are excellent resources for targeting the audience and making the communication precise, they are not always the best resources for other aspects of communication such as designing presentation slides, making the writing fluid, or clarifying guidelines for verb tense or paraphrasing sources. ${ }^{1}$ In addition, because graduate students historically make many of the same errors in their communications, institutions could save faculty mentors much time if ways to avoid those common errors could be imparted to large groups of graduate students.

To help graduate students communicate their research, some institutions offer semester-long graduate courses. Three examples occur at Ohio State University, ${ }^{3}$ the University of Wisconsin-Madison, ${ }^{4}$ and Colorado School of Mines. ${ }^{5}$ Although these courses have been successful at helping graduate students acquire research communication skills, these courses instruct only a small number of the graduate students. For instance, in three offerings from 2000 to 2004, the Colorado School of Mines course instructed only 38 students.

A strategy to impart communication skills to larger numbers of graduate students is through workshops. Those institutions with the resources to offer such workshops typically do so through their respective graduate schools and include graduate students from all colleges. Examples include the University of Texas at Austin, ${ }^{6} \mathrm{Texas} A \& \mathrm{M},{ }^{7}$ the University of California-Davis, ${ }^{8}$ and the University of Illinois at Urbana-Champaign. ${ }^{9}$ Because the content of these workshops is generally not available on the web or in publication (as the contents of many university courses are), no standards exist for the scope or depth of these workshops. Also, because assessments of these workshops are 
generally not published, no consensus exists on what works and what does not for meeting the communication needs of graduate students in engineering and science. Finally, because the workshops target such a wide range of writing - from the humanities to the sciences - the advice is often too general.

One workshop series that did target engineering graduate students occurred at the University of South Carolina. ${ }^{10}$ The series consisted of four graduate student workshops for professional communication. Each workshop, which lasted about 1.5 hours, focused on one of the following types of communication: teaching, writing a scholarly paper, writing a dissertation, or the communication associated with searching for a job. Relying on a combination of faculty mentors and a communication specialist, the workshops had two aims: (1) to reproduce the best mentoring advice of the faculty and (2) to give stylistic advice from a communication professional. By having both a research mentor and communication professional in the same room, these workshops tried to avoid the problem of cross-talk, which in this case would be contradictory advice about communication given to graduate students by research advisors and communication teachers.

In pursuing this strategy, the South Carolina workshops emphasized the process of research communication as much as, if not more than, the style. For instance, the workshop on writing a dissertation devoted 45 minutes to the process of getting words onto paper, but only 25 minutes on the style of dissertation writing. Granted, both perspectives are important, but the question arises whether such a short time can properly address the stylistic issues of communicating research.

Another workshop series that targeted engineering and science students had its origins at the national laboratories. ${ }^{11}$ This workshop series, which has been taught to more than 1000 professionals and graduate students, was formally tested on more than 400 graduate students at five different universities: Pennsylvania State University, the University of Illinois at Urbana-Champaign, the University of Oslo, the University of Texas at Austin, and Virginia Tech. This workshop series consisted of two components: one on research presentations and the other on research writing. Unlike the South Carolina workshop, this national laboratory workshop series focused most of its time on the style of writing and speaking.

Evaluations of this national laboratory workshop series found that more than $95 \%$ of participating students strongly agreed or agreed that the workshop series was a valuable experience. ${ }^{11}$ Also found was that the workshop series was more effective when accompanied by pre-workshop assignments in which the students attempted to communicate a portion of their research, and by follow-up sessions in which the students critiqued each others' research communications. Moreover, the teachings of the workshop series were better received when recruitment for the series occurred through the advising faculty members and when those faculty members were made aware beforehand of the approaches to gray-area stylistic issues, such as whether to use the first person in research documents.

This paper presents the development of a Norwegian national workshop to address this gap between what faculty members can, or have time to, provide and what graduate students need for communicating research. Drawing from the workshop series 
with its origins at the national laboratories, ${ }^{11}$ our 3-day workshop, given in English, also tried to establish a benchmark for the instruction of these critical skills. This workshop, which was a collaboration between Simula Research Laboratory in Norway and Pennsylvania State University in the United States, was funded primarily by the Norwegian firms of StatoilHydro and Telenor.

This paper discusses how the national workshop arose and was funded. Also presented is the selection process for the participants. Given next is the structure of the workshop, including the content of the three different segments. The paper concludes with a discussion of how this workshop will be assessed and whether it might serve as a model for other countries desiring to teach these communication skills to their graduate students.

\section{Origin and Funding of National Workshop}

In 2008, Simula Research Laboratory through the educational unit Simula School of Research and Innovation (SSRI) taught a sequence of two workshops on research communication for 12 of its Ph.D. students. The Laboratory, which performs research in information science, is internationally highly regarded within its fields of expertise and was awarded a Center of Excellence in biomedical computing in 2007 by the Research Council of Norway. SSRI, which is organized as a limited company co-owned by the Laboratory and selected industrial partners, offers $\mathrm{PhD}$ students and postdoctoral fellows at Simula professional courses that are usually not found in the university's curriculum. For the teaching of communication skills, SSRI has used the workshop series that arose from the national laboratories in the United States as a starting point. ${ }^{11}$ That series was well received in a 2004 offering at the University of Oslo.

The 2008 workshop at Simula Research Laboratory on communicating research had the following goals:

(1) achieving significant improvement in the research writing and presentation skills of the 12 graduate students, and

(2) providing a valuable learning experience to the technical staff of the Laboratory as well as to the Laboratory's technical collaborators.

To achieve these two goals, the workshop had a two-tier level of involvement: formal classes, which were open to all technical staff and collaborators with Simula Research Laboratory, and critique sessions, which were restricted to the twelve students from Simula.

Assessment of the workshop occurred through surveys of the participants and through assessment of two presentations by the 12 participants - one presentation occurring at the beginning of the workshop and the other occurring two months later. The surveys indicated that the formal class portions of the workshop were successful. For instance, on the question of whether the formal class on technical presentations was a valuable learning experience, the mean score was 6.3 out of 7 , with 7 representing excellent. In addition, the assessment of presentations given by the 12 participants indicated noticeable improvement in their presentation skills, from a 4.67 average at the beginning of the workshop to a 5.63 average two months later. 
Because of the success of this workshop, the idea arose to expand this workshop from 12 Ph.D. students at Simula Research Laboratory to 56 Ph.D. students in engineering and science from across Norway. If the workshop succeeded in improving the communication skills for a sizable number of students from across the country, not only would that finding serve to solidify confidence in the workshop, but would also serve to help diffuse the communication ideas of the workshop through the country. That diffusion would occur as graduate students went back to their respective research groups and made presentations and wrote documents that faculty and other students would see. The diffusion would also occur when those graduate students from the workshop provided critiques of the presentations and writings of their fellow graduate students at their home institutions.

The number of participants was constrained because we had only three people who were experienced enough with the workshop content and with critiquing presentations to serve as coaches for the critique sessions. Using the same size and schedule for the critique sessions in the 2008 workshop at Simula Research Laboratory, we established a maximum number of participants (68) whom we could handle in a 3-day workshop. The 3-day length of the workshop was chosen because that seemed to be a reasonable amount of time to request graduate students to leave their research projects, travel to a location in the country, and focus on these communication skills. Because writing critique sessions require significantly more time (both the time to read the manuscripts and the time to discuss the manuscripts), we decided to provide feedback on the writing in a different manner from what Simula had done in 2008.

Once we established the scope of the workshop, we needed to secure funds. The main portion of the funding was needed to provide a conference site with lodging and food for the participants. While we decided to require the graduate students to provide their own transportation to the conference site, the lodging and food for those 3 days would be free. Norway has large universities at the following locations: Oslo, Trondheim, Bergen, Tromsø, and Stavanger. Because the population center of Norway is in its southern region and because Oslo is by far the largest city and has direct trains connections with Trondheim, Bergen and Stavanger and daily flight connections with those cities and with Tromsø, we decided to have the workshop site in the Oslo area. Since the University of Oslo with its 35,000 students is the largest in the country, it would also be expected that a considerable number of participants is associated with that university. The size of Norway poses a challenge in creating a national workshop. To give one a sense for the length of Norway, consider the following analogy: If one were to flip the country on its southernmost point, the top of Norway would extend down below Rome.

Because the Research Council of Norway expressed interest early on in such a national workshop, we approached them first for funding. One addition that they requested for the workshop was a segment on communicating research to general audiences, including government officials. Although the Research Council still maintains an interest in the workshop, they had no precedent for funding such a workshop and in the end declined. However, we obtained funding from Norwegian institutions that work with Simula Research Laboratory. Those institutions were as follows: StatoilHydro, which is one of the largest oil and gas companies in the world; Telenor, a 
communications corporation; the University of Oslo; IT Fornebu; and the Norwegian Defense Research Establishment. In exchange for accepting their funding, which was about $\$ 95,000$, we allowed those institutions to have participant slots in the workshop. Where possible, those slots were to be for Ph.D. students working at those institutions.

\section{Selection Process of Participants for National Workshop}

In December 2008, Simula Research Laboratory prepared a brochure and web-site for the National Workshop and, in January 2009, sent out almost 1900 brochures $^{12}$ to contacts in different departments around the country. Follow-up correspondence revealed that all contacts had received and distributed the brochures to the students for whom they were responsible. In practice, the invitation reached almost all Norwegian Ph.D. students in engineering, the information sciences, the earth sciences, the physical sciences, and the life sciences.

Through the brochure, the web-site, and emails from the sponsors, students learned about the free workshop (the only expense being transportation) that was to occur on March 9-11, 2009. The deadline for the applications was February 1, 2009.

What was interesting about this mailing and the subsequent response is that it gauged the interest of Ph.D. students in learning such skills. Of the almost 1900 brochures submitted, $232 \mathrm{Ph}$.D. sent back applications for the workshop. That number is particularly high since this workshop was a pilot — most students did not have any word from their peers yet as to its value. Clearly, a demand for such a workshop exists.

Once the applications arrived, the next step was the selection process. Criteria for selecting the students were as follows: how far along the students were in their Ph.D. and diversity in gender, diversity in nationality, diversity in geographic location, and diversity in area of study. From the experience of the 2008 workshop at Simula, we decided that having first-year Ph.D. students would not be as effective, because those students are generally not far enough along in their research to be thinking about papers and presentations. Likewise, selecting students who were about to finish has been found not to be optimal because many of those students just want to complete their work and are not as willing to experiment with new ways to communicate their research.

Of the 68 participants for the workshop, 56 slots were for Ph.D. students and 12 were for research scientists. Of those 68 participants, the selection process produced a distribution in which 28 were female (41\%) and 40 were male (59\%). More interesting, those 68 participants represented 28 different countries and 25 different first languages. Figure 1 presents the distribution of countries represented by participants at the workshop. Note that 30 of the participants were Norwegian and the remainder came from the represented 27 other countries. These countries were spread across every continent except for Antarctica.

Table 1 presents the distribution of participants across the disciplines. This distribution of disciplines reflects the distribution of engineers and scientists in Norway. Table 2 presents the distribution of institutions in which the participants are studying or working. As shown in Table 2, more than half of the participants came from Norway's 
two largest institutions: the University of Oslo and the Norwegian University of Science and Technology in Trondheim.

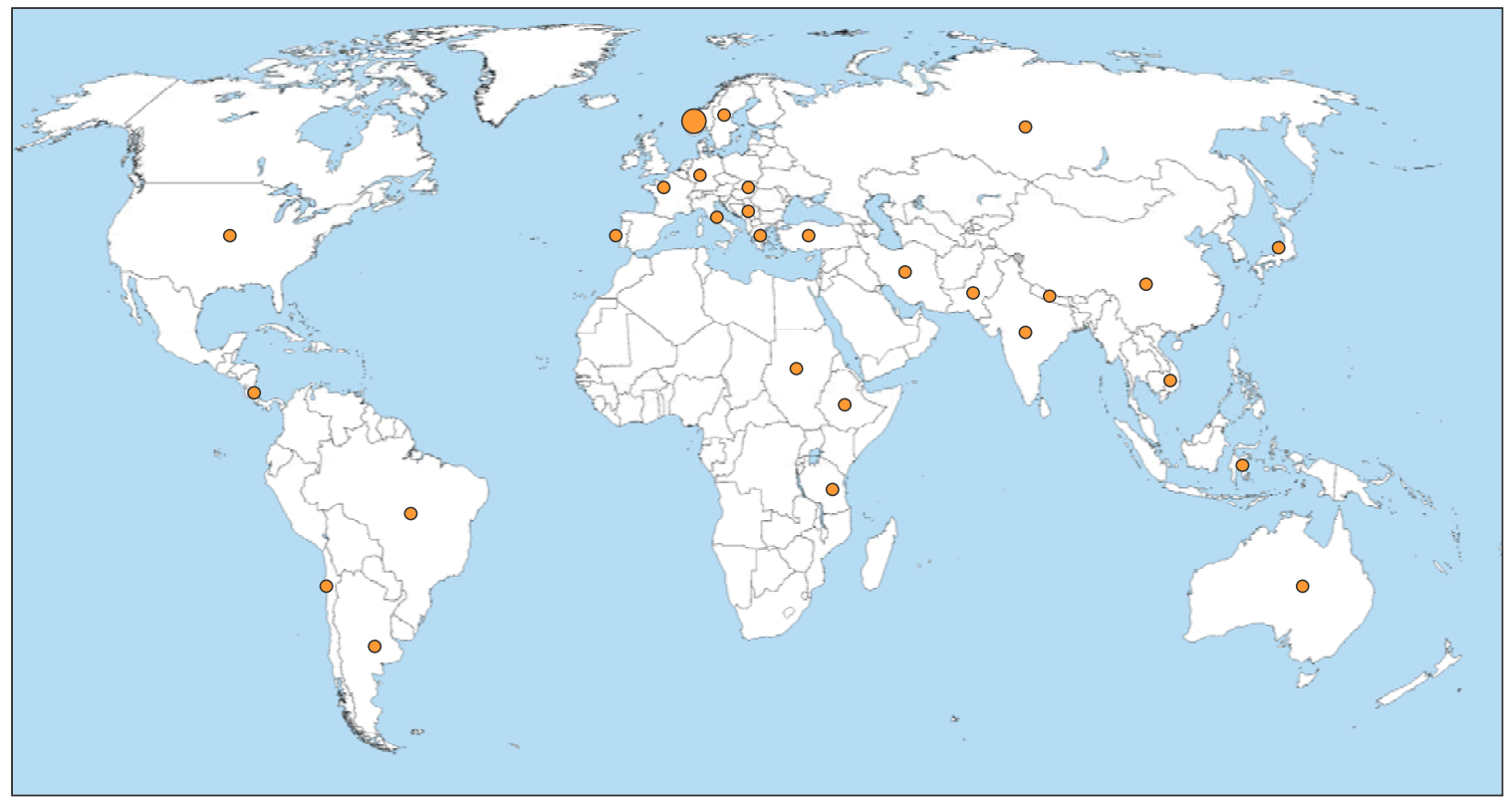

Figure 1. Distribution of the 28 home countries of the participants. All continents, except for Antarctica, are represented. In addition, the participants represented 25 different first languages.

Table 1. Distribution of disciplines for the workshop.

\begin{tabular}{|l|c|}
\hline Discipline & Number \\
\hline Informatics, Informational Science, Computer Science & 20 \\
\hline Math Physics, Astronomy, Civil Engineering & 12 \\
\hline Biological Sciences & 12 \\
\hline Electrical Engineering, Telecommunications & 8 \\
\hline Geology, Meteorology, Geophysics & 8 \\
\hline Chemistry, Material Science & 8 \\
\hline
\end{tabular}

Table 2. Distribution of Norwegian Institutions of the participants.

\begin{tabular}{|l|c|}
\hline Institution (Abbreviation, Location) & Number \\
\hline University of Oslo (UiO, Oslo) & 29 \\
\hline Norwegian University of Science and Technology (NTNU, Trondheim) & 16 \\
\hline Norwegian University of Life Sciences (UMB, Aas) & 6 \\
\hline University of Bergen (UiB, Bergen) & 5 \\
\hline University of Stavanger (UiS, Stavanger) & 2 \\
\hline University of Tromsø (UiT, Tromsø) & 2 \\
\hline University of Agder (UiA, Agder) & 2 \\
\hline Other Universities & 5 \\
\hline Simula Research Laboratory & 1 \\
\hline Total & 68 \\
\hline
\end{tabular}




\section{Structure of the National Workshop}

As mentioned, the national workshop consisted of three segments: (1) research presentations for technical audiences, (2) research writing to technical audiences, and (3) research presentations to general audiences. Preparation assignments, which are described in Appendix A, existed for the first two segments. To manage the submission and review of the preparation assignments, we used slightly modified version of the open source learning platform Dokeos (www.dokeos.com). On this platform, we also created forums to discuss aspects of communication for which we anticipated the participants would have questions. In early February, a pre-Workshop survey was taken to serve as a baseline for assessing whether the Workshop led to any self-assessed improvements. Also serving as a baseline for their communication skills was the collection of an abstract and a set of slides for a recent presentation that they had given about their research.

Figure 2 presents the schedule for the 3-day workshop, which occurred on 9-11 May 2009. As can be seen, the workshop began with the formal class for the segment on scientific presentations to technical audiences. That was followed by presentation critique sessions for the participants. In these critique sessions, participants either presented, reviewed, or simply listened as audience members. All presentations were filmed and were downloaded to the web platform so that the participants can review their presentations and the critique discussions that immediately followed. The last day concluded with the formal class portions on writing documents for technical audiences and making presentations to the general public. The following three subsections discuss these three segments and present preliminary assessments of each.

\section{Research Presentations to Technical Audiences}

The first segment of the workshop, which was based on the presentation segment of the national laboratory workshop, had the goal of preparing participants to make presentations about their research at conferences, before research groups, and before dissertation committees. As revealed in the schedule shown back in Figure 2, two days of the national workshop were devoted to this segment. During these two days, each participant attended five hours of formal class, participated in a 2-hour session in which he or she and three other participants presented their research and were critiqued, and two 2-hour sessions in which the participant serve as a reviewer or audience member for other presenting participants. Participants also spent significant time before the workshop submitting slides for this portion and then receiving a critique from one of the instructors on those slides. One reason that we devoted so much time in the workshop to this segment was that this segment taught communication principles, such as targeting audience, purpose, and occasion, that pertained to the other two situations for research communication: presenting to a general audience and writing for a technical audience.

Another reason that the first segment required so much time was that this segment taught a relatively new structure for presentation slides that challenges the status quo. This structure, called the assertion-evidence structure, ${ }^{13,14,15}$ calls on the presenter to craft a succinct sentence assertion for each slide and then to support that assertion with visual evidence. In this structure, bullet lists do not occur. 


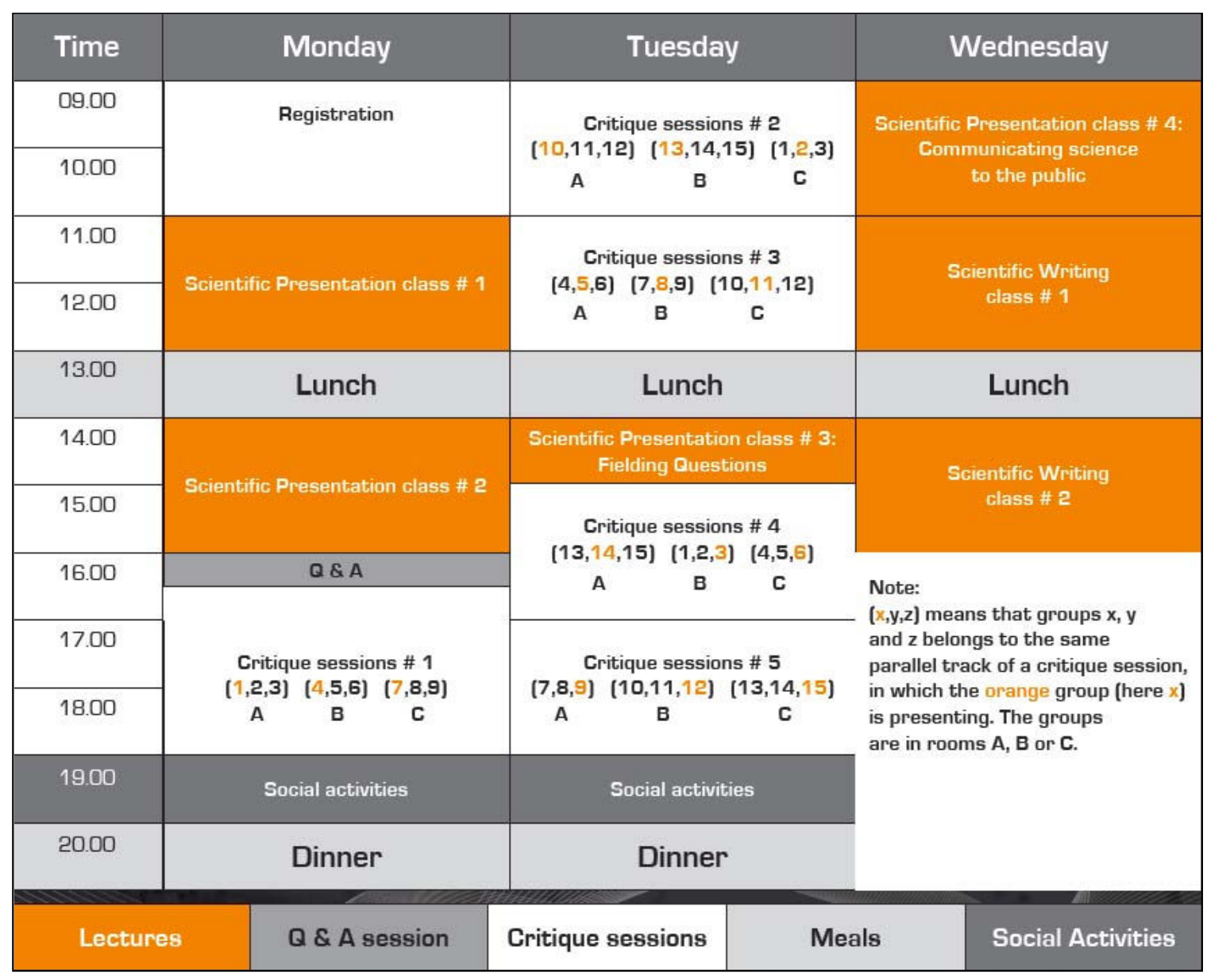

Figure 2. Three-day schedule of the workshop, which occurred at Voksenåsen, a resort just north of Oslo.

This assertion-evidence structure requires significantly more effort on the part of the presenter. ${ }^{14}$ One reason is that this structure calls for a headline that is a succinct sentence (no more than 2 lines) that states the main assertion of the slide as opposed to a phrase headline, as is typically created, that simply identifies the topic. Another reason is that the structure requires visual evidence (photographs, drawings, diagrams, graphs) as opposed to a bullet list. Still, a third reason is that the structure requires the participant to challenge the layout and typography defaults of PowerPoint so that white space occurs between elements in the slide. Finally, because the structure does not allow for many words on the slides, presenters have to prepare enough that they can speak to the audience as opposed to simply speaking from the slides. Because the structure requires much more effort from the presenter, the initial resistance to the structure is high. ${ }^{16}$ Theoretically, the advantages in having a more effective presentation should make up for the additional effort. ${ }^{17}$ However, the question was whether the participants would recognize that advantage and adopt the structure.

The preparation assignments provided a preliminary answer to this question. The first preparation assignment, which was due February 16, called upon participants to submit the best set of presentation slides that they had created in the part two years. This assignment indicated what slide structure the participants were currently using. Although 
we have not yet formally assessed the statistics on this preparation assignment, more than three-fourths of the submissions from this assignment followed the topic-subtopic structure that is the default of PowerPoint. ${ }^{17}$ In addition, almost all of those submissions that did not arose from participants connected with Simula Research Laboratory, which has a strong contingency of scientists who follow the assertion-evidence structure. The submissions for the first preparation assignment, together with the initial survey, form the baseline description of the participants' performance prior to the workshop. This information will be used in later assessments of the effect of the teaching.

The second preparation assignment, which was due one week later, then called upon participants to prepare a set of slides that followed the assertion-evidence structure. These slides were to be used in the presentations that the participants were to give at the workshop. Because this structure requires much more effort on the part of the presenter, ${ }^{16}$ we had anticipated that resistance would occur, and it did. For instance, Figure 3 presents an exchange between participant and instructor in the forum section of the web platform. This exchange involves a discussion of whether the assertion-evidence template (and essentially the assertion-evidence slide structure) was appropriate for different disciplines. Although this exchange involved just one participant and one instructor, the exchange was viewed 95 times, which is twice as many times as any other forum thread and well more than the number of participants in the workshop.

When the second preparation assignment was submitted, we evaluated how well the participants had adopted the structure. This evaluation involved a 5-point scale:

1: structure not adopted at all

2: structure superficially adopted

3: structure significantly adopted

4: structure primarily adopted

5: structure fully adopted

For the 67 participants who submitted this assignment, we had the following breakdown of adoption, which is considered high ${ }^{16}$ for adoptions of the assertion-evidence slide structure, especially when the potential adopters have not received a formal class on the structure:

1: 04

2: 13

3: 19

4: 21

5: 11

Just before the workshop, another survey was issued to assess the effect of the preparation assignments on the participants. At present, we are still processing the results of this survey.

On 9 March 2009, the formal class on research presentations to technical audiences occurred. Presented in Table 3 are the main topics that were covered in this segment and the times allotted for each. Likewise, given in this table are the teaching strategies used: discussion of topic, analysis of examples, and exercises. The order of the strategies reflects the emphasis on that strategy with the first strategy emphasized the most. A post-workshop survey has been issued and those results assessing the value of 
the formal class will be presented in a future publication. Furthermore, another survey is planned for late 2009, trying to measure longer-term effects of the teaching.

Participant: (name removed) 2009-02-17 13:04:41

Michael Alley (Instructor) 2009-02-17 23:10:21

\section{Template is not always helpful}

$\mathrm{Hi}$, I have started using the template for the 2nd assignment. Although I understand the reasons it's built as it is, I am having problems defining my assertion headline while having to reject a lot of details in the body of the slide. Also, images are not always possible to have for every assertion headline. What should be done in this case?

\section{Re: Template is not always helpful}

Thank you for your comment. I understand that this approach is much more difficult, but what it comes down to is what kind of visual aid will help the audience understand and remember the content of the presentation. The template is essentially a blank slide that calls on you to place the most important assertion of the slide at the top and to support that assertion visually (with photos, drawings, diagrams, graphs, or equations). In the body of the slide, words are used only where necessary for helping the audience understand that visual evidence.

If you do not have an assertion, then perhaps a visual aid is not needed for that part of the presentation. That is no problem. You can simply blank the screen and speak, and that would be refreshing because a common criticism of PowerPoint presentations is that most presenters show too many slides. If you do have an assertion but cannot think of a way to support it visually, then you have to be careful. If you insert supporting text onto the slide (PowerPoint's default), then you can easily overwhelm the audience with too much text. In such a case, cognitive psychology research says that the audience would understand more if you blanked the slide and just spoke.

The point is that any slides projected should be designed for the audience. My suggestion is that you create slides only for the portions of your presentation in which you have assertions. Then, rather than placing your speaking points in the body of the slide, place an image, graph, or equation that would be part of your spoken argument supporting that assertion.

Figure 3. Exchange on forum about assertion-evidence structure that was viewed 95 times - twice as many times as any other exchange of the forum.

Table 3. Topics of segment on presenting research to technical audiences.

\begin{tabular}{lcl} 
Topic & $\begin{array}{l}\text { Time } \\
(\mathrm{min})\end{array}$ & Strategies to teach topic \\
\hline Audience, purpose, and occasion & 20 & Discussion, exercise \\
Structure: Orienting the audience & 20 & Examples, discussion, exercise \\
Structure: Being persuasive & 20 & Examples, discussion \\
Visual Aids: Problems with the current practice of slides & 20 & Examples, discussion, exercise \\
Visual Aids: Argument for the assertion-evidence structure & 60 & Examples, discussion, exercise \\
Visual Aids: Strong slide examples from research presentations & 40 & Examples, discussion, exercise \\
Delivering presentations & 60 & Examples, discussion
\end{tabular}


After the formal class of research presentations to technical audience, the workshop called for all the participants to make a presentation and to receive critiques of that presentations. Because all of the slides were collected and the presentations have been filmed, we are in a position to assess to what extent the participants adopted the principles of the workshop, including the assertion-evidence slide structure.

\section{Writing Research Documents to Technical Audiences}

The second segment of the workshop, writing research documents to technical audiences, was to prepare participants for writing conference papers, journal papers, and dissertations. The preparation assignment for this segment called upon participants to prepare and submit a summary of their research. This summary was used by participants for critiquing exercises during the formal part of the writing class. In the formal class, common weaknesses of these summaries were emphasized. Running a half day, this formal class presents participants with scores of examples. The strategy was to have the participants discover what makes for strong research communication by examining many before-revision and after-revision examples, such as those shown in Figures 4 and 5. All examples have been culled from research documents.

Weak examples, such as the ones shown in the left side of Figure 4 and the top portion of Figure 5, were carefully chosen according to the following two criteria: (1) the example contains common problems in research writing, and (2) the example contains only one or two types of problems. For instance, the weak title on the left side of Figure 4 has two common weaknesses of titles: not targeting the audience (a Congressional subcommittee in this case), and not containing small words such as to or for to separate the details. Likewise, the two main shortcomings of the top abstract of Figure 5 are that the verbs are weak and that the abstract does not divulge the main research result.

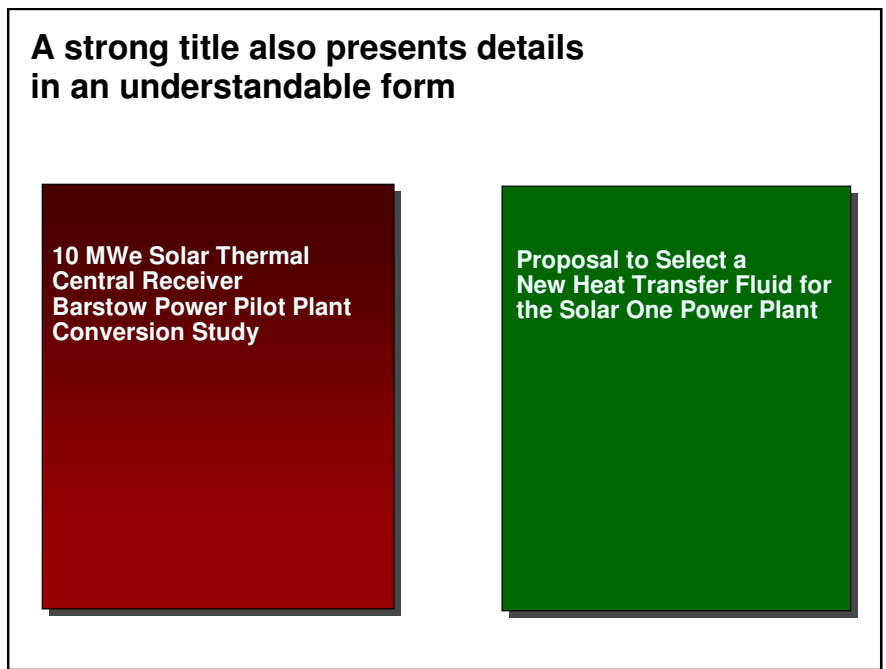

Figure 4. Sample slide from segment on research writing. ${ }^{11}$ This slide presents a before-revision and afterrevision example from a research proposal. 


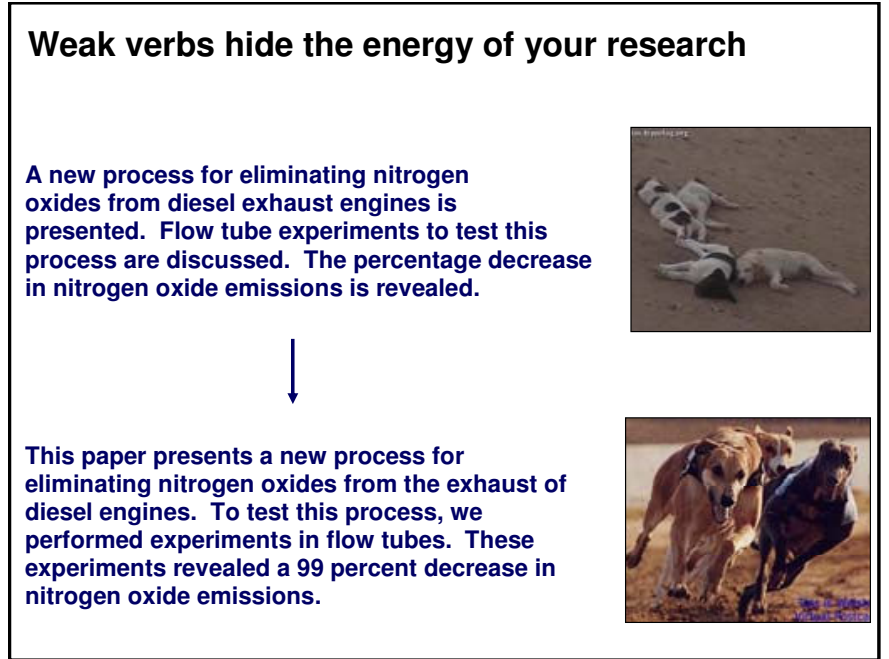

Figure 5. Another sample slide from segment on research writing. ${ }^{11}$ This slide presents a before-revision and after-revision example from the abstract of a research paper.

To have participants discover (rather than just be told about) these weaknesses, the formal class used animation on presentation slides to withhold the revision until the students have articulated the weaknesses. In addition to relying on this Socratic Method for evaluating examples, the writing segment had the students work through exercises on various aspects of style and form. These exercises include having the participants pair up and assess each others' titles and first sentences and having the participants construct a table for their literature review that visually shows how their research differs from that of other researchers in the field.

Presented in Table 4 are the main topics and times for the workshop on research writing. Not included in these topics are special issues faced by students for whom English is a second language. Although second language issues pose serious hurdles for foreign students, most institutions have special programs to address those needs.

Table 4. Topics of segment of writing research documents to technical audiences.

\begin{tabular}{lcl} 
& Time & \\
Topic & (min) & Strategies to teach topic \\
\hline Targeting audience and purpose & 20 & Discussion, exercise \\
Actually sitting down to write & 10 & Discussion \\
Structuring the beginning & 30 & Examples, exercises, discussion \\
Structuring middles and endings & 15 & Examples, discussion \\
Making sentences clear & 45 & Examples, discussion, exercises \\
Making sentences energetic & 30 & Examples, exercises, discussion \\
Making sentences connect & 30 & Examples, exercises, discussion \\
Making illustrations persuade & 20 & Examples. discussion \\
Avoiding errors of grammar, punctuation, usage, and format & 0 & Take-home exercise with answer key
\end{tabular}

As with the first segment of the course, we are using a post-workshop survey to determine whether the participants self report any improvements to their writing skills. Because this segment relied solely on a preparation assignment and a formal class with exercises as opposed to those two elements in combination with a formal critique session, we do not anticipate that the self-reported gains will be as high as for the first workshop segment. 


\section{Research Presentations to General Audiences}

The third and final segment, communicating research to the general public, tried to address a need that has become an important goal of the Research Council of Norway and the National Institutes of Health in the United States. This workshop segment has the goal of teaching participants how to give general audiences what Richard Feynman called an "honest" understanding of the work. The content for this segment arose from an examination of successful general audience presentations, given by well known figures such as Robert Ballard, Janine Benyus, and Brian Cox.

In this segment, participants examined four perspectives on communicating to a general audience: structure (the strategy for the communication), speech (the words spoken), visual aids, and delivery. For the structure perspective, participants were exposed to the importance to story telling. In addition, participants were taught four different entry points for a research presentation, with examples shown for each. For the speech perspective, we tried to show participants how to select the most effective details and how to craft valuable analogies. For the perspective of visual aids, we tried to teach participants the value of using images and the importance of avoiding of the all-toooften-used bulleted list. Finally, for the delivery perspective, we emphasized to participants that the expectations of general audiences were higher than the delivery expectations of scientific audiences. Presented in Table 5 are the main topics and times for the workshop on communicating to the general public. This workshop served as the premiere of this segment. In the post-workshop survey, we hope to determine the effect of this segment.

Table 5. Topics of segment on communicating to a general audience.

\begin{tabular}{lcc} 
Topic & $\begin{array}{l}\text { Time } \\
\text { (min) }\end{array}$ & Strategies to teach topic \\
\hline Audience, purpose, and occasion & 20 & Examples, discussion, exercise \\
Structure: Telling a story and finding an entry point & 30 & Examples, discussion, exercise \\
Speech: Choosing the most effective details and crafting analogies & 30 & Examples, discussion, exercise \\
Visual aids: Designing visual aids to target a general audience & 20 & Examples, discussion \\
Delivery: Meeting the expectations of a general audience & 20 & Examples, discussion
\end{tabular}

\section{Conclusion}

In March 2009, we ran and began assessing a communication workshop for Norwegian $\mathrm{Ph}$.D. students in engineering and science. The workshop, which was funded by Norwegian institutions such as StatoilHydro and Telenor, had 68 participants, of whom 60 were Ph.D. students. The participants represented 28 different countries and 25 different native languages. Because all the major universities in Norway were represented, we hope to begin diffusing the unique communication strategies of this workshop throughout the country. These strategies address the challenges of presenting research to a technical audience, documenting research for a technical audience, and communicating research to general audiences.

Of the almost $2000 \mathrm{Ph}$.D. students contacted about the workshop, 232 submitted applications. That high number revealed the interest in this subject, especially given that the workshop required the participants to travel to the workshop location on their own, to 
perform three preparation assignments for the workshop, and to devote 3 full days to the workshop activities. That high number also revealed that much interest remains among the Ph.D. student population of Norway for this type of workshop.

Assessment of the workshop is occurring through surveys of the participants and comparisons of the presentation slides created by participants before the workshop with slides created after the participants have received workshop instruction.

If the assessment reveals that this workshop is a valuable means for communicating these critical communication skills to Ph.D. students, then this workshop could provide a model and a benchmark for similar efforts in Norway and in other countries. A possible way to scale up this workshop to serve more than 68 participants over a 3-day period would be to train more coaches.

\section{Appendix A: Preparation Assignments for the National Workshop}

The following three preparation assignments for the national workshop on Communicating Scientific Research are designed to help the participants get the most benefit out of the teaching. The assignments are also important for us to know what the strengths of the participants are and where opportunities exist for improvement. All preparation materials are to be submitted to the dropbox of the workshop's web platform.

\section{Preparation Assignment 1: Due Monday, February 16}

Think about the best scientific presentation that you have made in the past two years. The presentation could have been about your current research project, another research project, or a class project. For that presentation, please send the set of slides that you used, either as a PowerPoint file or a pdf file. Also submit a short abstract of 6-10 lines that explains the purpose of that presentation and the main point that you were trying to communicate. The abstract can be a Word file, a pdf file, or simply a plain text file.

This assignment will show us how you have been preparing presentations prior to the workshop, and will allow us to provide tailored feedback to the material that you are going to prepare as part of the next assignment.

\section{Preparation Assignment 2: Due Monday, February 23}

In the workshop, we will introduce a new way to structure slides that is gaining popularity among research scientists and engineers. This structure, named the assertion-evidence structure, is a valuable tool for you to master.

To begin learning this structure, please download the PowerPoint template (slide_template.ppt) from the Documents folder on the web platform and use this template to create five to seven slides that follow this structure. Have your slides present either an overview or a portion of your research (10-12 minutes of content). Your set of slides should include the following:

a title slide,

a background slide (optional),

a mapping slide (sometimes called an outline slide), 
two to three slides to form the middle of the presentation, and

a conclusion slide.

Because the assertion-evidence slide design is significantly different from the defaults of Microsoft PowerPoint, it is important that you begin creating the slides with the provided template. Also, because creating slides using this structure takes more time, please do not wait until the last day to begin this assignment. To help us quickly identify your file, please name your file according to the format Lastname_Firstname_prep.ppt before you upload it.

As with Preparation Assignment 1, please include a short abstract of 6-10 lines that explains the purpose of your presentation and the main point that you will try to communicate. If you need a starting point for authoring your abstract, please consider the abstract template (abstract template.doc) that is also available in the Documents folder. Note that all abstracts will be collected into a booklet that will be made available to all participants in the workshop.

Between the deadline for uploading your material and the actual workshop, you will receive a short, written feedback on your slide design and abstract through the web platform. Taking the feedback into account, you may want to revise and resubmit your documents.

Please note that you will be expected to give your presentation live as part of the group exercises during the workshop. Immediately following your presentation, you will receive feedback from your peers and from the group's instructor.

\section{Preparation Assignment 3: Due Monday, March 2}

At the top of a page, write the working title of your research project and then for the rest of the page, draft a summary that includes the motivation for your research, the scope of your research, and any major findings (if you have them). For the summary, please use 12-point type and 1.5-line spacing. The finished document should be uploaded to the web platform using the Dropbox tool.

\section{References}

1 Craig, Jennifer, "Writing Strategies for Graduate Students," Proceedings of the 2005 American Society for Engineering Education Annual Conference and Exhibition (Nashville, TN: ASEE, 2005).

2 U.S. Dept. of Education, Profiles of Faculty in Higher Education Institutions, 1988, Report No. NCES 97-080 (Washington, D.C.: National Center for Education Studies, 1991).

3 Wilkins, John, Carla Allen, and Tom Barrett, "Writing and Speaking About Physics and Astronomy," Physics 596, http://physics.ohio-state.edu/ wilkins/writing/ (Columbus, OH: Ohio State, 2007).

4 Nicometo, Christine G., and Paul Ross, "Hanging on to the Cutting Edge: Revising Online Graduate Communication Courses for Practicing Engineers," presentation, 2006 American Society for Engineering Education Annual Conference and Exhibition (Chicago: ASEE, 2006). 
5 Leydens, Jon A., and Barbara M. Olds, "Publishing in Scientific and Engineering Contexts: A Course for Graduate Students," IEEE Transactions on Professional Communication, vol. 50, no. 1 (March 2007), pp. 45-56.

6 Darwin, Tommy, Professional Development, "Dissertation and Thesis Writing," http://www.utexas.edu/ogs/pdce/workshops/ (Austin, TX: University of Texas, 7 March 2007).

7 Office of Graduate Studies, "Writing an Abstract," http://ogs.tamu.edu/current/graduate-studentworkshops (College Station, TX: Texas A\&M, 17 February 2009).

8 University Writing Program, "Graduate Student Workshop Program (Writing Across the Curriculum)," $\mathrm{http} / / /$ writing.ucdavis.edu/program-information/the-workshop-program/ (Davis, CA: University of California-Davis, 6 February 2009).

9 Lambeth, Greg, Career Services, "Dissertation Writing Workshop," http://www.grad.uiuc.edu/careerservices/workshops/ (Urbana-Champaign: University of Illinois, 7 March 2007).

10 Alford, E.M., and P.E. Stubblefield, "Mentoring Engineering Graduate Students in Professional Communications: An Interdisciplinary Workshop Approach," Proceedings of the 2002 American Society for Engineering Education Annual Conference and Exhibition (Montreal, Canada: ASEE, 2002).

11 Alley, M., Srajek, L., Johnson, A.W., and M. Stickler (2007, October 13). Evaluation of two workshops for graduate students on communicating research in engineering and science. Proceedings of the 2007 Frontiers in Education Conference. Milwaukee, WI.

12 Sundet, Marianne M. \& Bruaset, Are M. (2009). Workshop: Communicating scientific research. www.simula.no/education/ssri/communication-workshop. Simula School of Research and Innovation AS.

13 Atkinson, Cliff (2005). Beyond Bullet Points: Using Microsoft PowerPoint to Create Presentations That Inform, Motivate, and Inspire. Redmond, WA: Microsoft Press.

14 Alley, Michael, and Katherine A. Neeley (2005). Rethinking the Design of Presentation Slides: A Case for Sentence Headlines and Visual Evidence. Technical Communication, 52 (4), 417-426.

15 Doumont, Jean-luc (2007). Creating Effective Presentation Slides.

http://ewh.ieee.org/soc/pcs/index.php?q=node/111, audio file. IEEE Professional Communication Society.

16 Neeley, K. A., Alley, M., Nicometo, C. \& Srajek, L. (2009). Teaching against the grain: a case study of teaching a slide design that challenges PowerPoint's defaults. Technical Communication (under review).

17 Garner, J., Alley, M, Gaudelli, A. \& Zappe, S. (2009). Common use of PowerPoint versus assertionevidence slide structure: a cognitive psychology perspective. Technical communication (under review). 